\title{
Comparison of Three Methods for Wind Turbine Capacity Factor Estimation
}

\author{
Y. Ditkovich and A. Kuperman \\ Hybrid Energy Sources Laboratory, Department of Electrical Engineering and Electronics, Ariel University Center of Samaria, \\ 40700 Ariel, Israel \\ Correspondence should be addressed to A. Kuperman; alonku@ariel.ac.il
}

Received 6 August 2013; Accepted 7 November 2013; Published 22 January 2014

Academic Editors: M. Cepin and P. Del Río

Copyright (C) 2014 Y. Ditkovich and A. Kuperman. This is an open access article distributed under the Creative Commons Attribution License, which permits unrestricted use, distribution, and reproduction in any medium, provided the original work is properly cited.

\begin{abstract}
Three approaches to calculating capacity factor of fixed speed wind turbines are reviewed and compared using a case study. The first "quasiexact" approach utilizes discrete wind raw data (in the histogram form) and manufacturer-provided turbine power curve (also in discrete form) to numerically calculate the capacity factor. On the other hand, the second "analytic" approach employs a continuous probability distribution function, fitted to the wind data as well as continuous turbine power curve, resulting from double polynomial fitting of manufacturer-provided power curve data. The latter approach, while being an approximation, can be solved analytically thus providing a valuable insight into aspects, affecting the capacity factor. Moreover, several other merits of wind turbine performance may be derived based on the analytical approach. The third "approximate" approach, valid in case of Rayleigh winds only, employs a nonlinear approximation of the capacity factor versus average wind speed curve, only requiring rated power and rotor diameter of the turbine. It is shown that the results obtained by employing the three approaches are very close, enforcing the validity of the analytically derived approximations, which may be used for wind turbine performance evaluation.
\end{abstract}

\section{Introduction}

Since the wind blows inconsistently, wind turbines barely operate at their rated power. Therefore the concept of capacity factor $(\mathrm{CF})$ is usually engaged to assess the expected wind turbine energy delivery [1]. In order to calculate the CF, wind probability distribution function (PDF) and turbine power performance curve are required. The capacity factor, given by the ration between the average and rated turbine power, is usually formulated as

$$
\mathrm{CF}=\frac{E[P]}{P_{R}}=\frac{1}{P_{R}} \int_{0}^{\infty} P(v) f(v) d v,
$$

where $E[\cdot]$ is the mean value operator, $P(v)$ and $P_{R}$ are the power curve and rated power of the turbine, respectively, and $f(v)$ is the wind PDF. In reality, the power curve of the turbine is a discrete series rather than a continuous function, and the wind PDF in (1) is the result of fitting the discrete raw wind data to an a priori assumed PDF. Hence, (1) is actually an approximation. Nevertheless, several analytic solutions of (1) have been presented in the literature [2,3], allowing thorough understanding of the factors, affecting the CF. The more accurate (referred to as quasiexact thereafter) solution, taking into account the original rather than processed wind speed and power curve data, exists in a spreadsheet form only [4] and its outcome is given by a numerical value without any insight into the $\mathrm{CF}$ formation. Nevertheless, both mentioned methods are not much of a help when very little is known about a site and wind turbine and it is desired to quickly and fairly accurately predict the annual energy yield. A pretty handy and accurate (within 10\%) solution was proposed in [4], where the authors demonstrated that, for midrange Rayleigh winds (5-9 m/s), the CF is a linear function of the average wind speed, depending on the turbine rated power and rotor blade diameter only. Unfortunately, the linear approximation is no longer valid for the winds outside the mentioned range and a nonlinear approximation of $\mathrm{CF}$ valid in the whole feasible speed range was proposed in [5].

In this paper, the three approaches to calculating the CF are reviewed and then compared using a case study. It is 


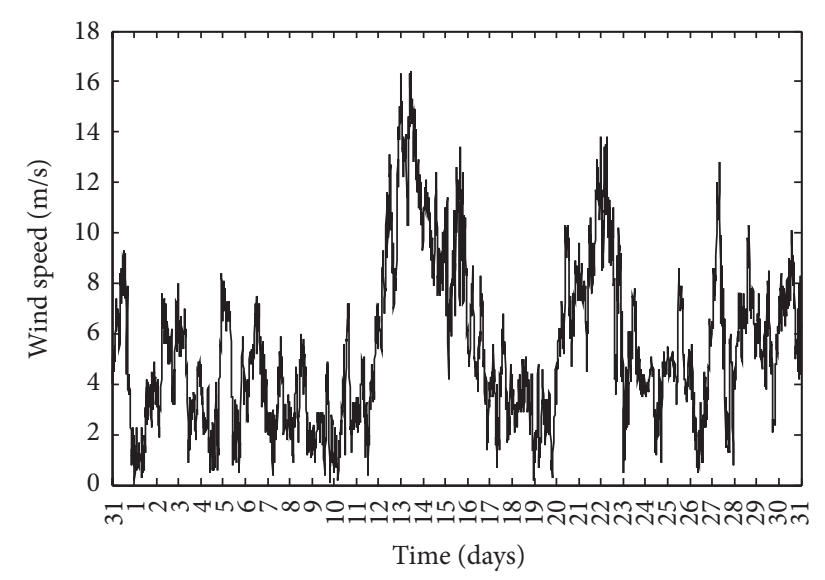

FIGURE 1: A typical monthly wind speed raw data.

shown that the obtained results are similar, justifying the use of analytically derived relations in spite of the fact that they describe an approximate solution only. Hence, analytical derivations of additional merits of wind turbine performances which rely on capacity factor (such as Turbine Performance Index $[6,7]$ and Turbine-Site Pairing Performance [8]) are justified and the results obtained using these relations are reliable.

\section{The Wind Data}

The wind speed data is usually provided by meteorological stations as raw matrix of wind speed versus time at $10 \mathrm{~m}$ height, while sample times vary from 10 minutes to 1 day. In reality, the sample time is much higher than stated and the available data sample is actually an average of tens to thousands of faster samples. An example of monthly wind speed raw data represented by 10 -minute samples is shown in Figure 1.

The raw vector can be either transformed into a histogram (discrete PDF) or fitted to a known continuous PDF, typically of Weibull type, as shown in Figure 2. When creating a histogram, the bins are typically chosen to be $1 \mathrm{~m} \cdot \mathrm{s}^{-1}$ wide to match the resolution of the manufacturer-provided turbine power curve data (explained in Section 3), resulting in the following discrete PDF:

$$
f_{\mathrm{HST}}(v)=f\left(v_{i}\right), \quad v_{i}-0.5 \leq v<v_{i}+0.5,
$$

where $f\left(v_{i}\right)$ is the magnitude of the histogram bin, centered at $v_{i}$.

As to Weibull fitting, several methods of deriving Weibull parameters from the raw data were compared in [9]. The maximum likelihood estimates of the Weibull distribution parameters are typically employed in dedicated software packages, for example, MATLAB.

Weibull PDF is defined as

$$
f_{\mathrm{WBL}}(v)=\frac{k}{c}\left(\frac{v}{c}\right)^{k-1} e^{-(v / c)^{k}}
$$

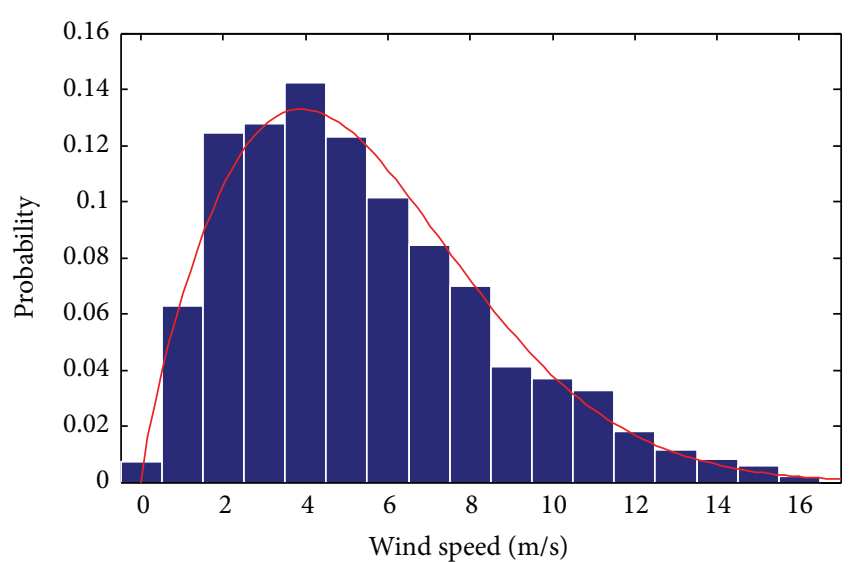

Histogram Weibull fit

FIgURE 2: Histogram and Weibull PDF fit of wind speed raw data of Figure 1.

with parameters $c$ and $k$ being related to the site wind speed mean and standard deviation as

$$
\begin{gathered}
\mu_{v}=c \Gamma\left(1+\frac{1}{k}\right), \\
\sigma_{v}=c \sqrt{\Gamma\left(1+\frac{2}{k}\right)-\Gamma^{2}\left(1+\frac{1}{k}\right)},
\end{gathered}
$$

respectively, where

$$
\Gamma(x)=\int_{0}^{\infty} t^{x-1} e^{-t} d t
$$

is the complete Gamma function. In case the wind raw data of a site is absent, but the mean and standard deviation of the wind speed are known, Weibull PDF is usually assumed and its parameters are calculated using (4).

A particular (and very common) case of Weibull PDF with $k=2$ is called Rayleigh PDF and is given by

$$
f_{\mathrm{RLH}}(v)=\frac{2 v}{c^{2}} e^{-(v / c)^{2}}
$$

with scale parameter $c$ being related to the site mean wind speed as

$$
\mu_{v}=\frac{\sqrt{\pi}}{2} c .
$$

\section{Turbine Power Curve}

The power production of a wind turbine is associated with one of the two nonzero regions of the power curve: the nonrated region for wind speeds between the cut-in speed $v_{C}$ and the rated speed $v_{R}$ or the rated region for wind speeds between the rated speed and the furling (or cut-out) speed $v_{F}$. The turbine power curve is usually supplied by the manufacturer as $N$-point discrete series $\left\{v_{i}, P\left(v_{i}\right)\right\}, i=$ $1, \ldots, N$, with $v_{i}-v_{i-1}=1$ for all $i$; that is, the data resolution 
TABLE 1: NEG Micon 1000/60 fixed speed turbine power curve data.

\begin{tabular}{lccccccccccccc}
\hline Speed $\left(\mathrm{m} \cdot \mathrm{s}^{-1}\right)$ & 1 & 2 & 3 & 4 & 5 & 6 & 7 & 8 & 9 & 10 & 11 & 12 & 13 \\
\hline Power $(\mathrm{KW})$ & 0 & 0 & 0 & 33 & 86 & 150 & 248 & 385 & 535 & 670 & 780 & 864 & 924 \\
\hline Speed $\left(\mathrm{m} \cdot \mathrm{s}^{-1}\right)$ & 14 & 15 & 16 & 17 & 18 & 19 & 20 & 21 & 22 & 23 & 24 & 25 & 26 \\
Power $(\mathrm{KW})$ & 964 & 989 & 1000 & 998 & 987 & 968 & 944 & 917 & 889 & 863 & 840 & 822 & 0 \\
\hline
\end{tabular}

TABLE 2: NEG Micon 1000/60 fixed speed turbine data.

\begin{tabular}{lcccc}
\hline Cut-in speed, $v_{C}\left(\mathrm{~m} \cdot \mathrm{s}^{-1}\right)$ & Rated speed, $v_{R}\left(\mathrm{~m} \cdot \mathrm{s}^{-1}\right)$ & Cut-out speed, $v_{F}\left(\mathrm{~m} \cdot \mathrm{s}^{-1}\right)$ & Rated power, $P_{R}(\mathrm{KW})$ & Hub height, $H(\mathrm{~m})$ \\
\hline 3.5 & 16 & 25 & 1000 & 70
\end{tabular}

TABLE 3: 6th-order fitting coefficients of NEG Micon 1000/60 power curve.

\begin{tabular}{cccccccc}
\hline$i$ & 0 & 1 & 2 & 3 & 4 & 5 & 6 \\
\hline $\mathrm{a}_{1 i}$ & -2.9 & 2.3 & -0.72 & 0.11 & $-9.1 \cdot 10^{-3}$ & $0.37 \cdot 10^{-3}$ & $-5.8 \cdot 10^{-6}$ \\
$\mathrm{a}_{2 i}$ & 12 & -3.5 & 0.45 & -0.029 & $1 \cdot 10^{-3}$ & $-0.18 \cdot 10^{-4}$ & $1.4 \cdot 10^{-7}$ \\
\hline
\end{tabular}

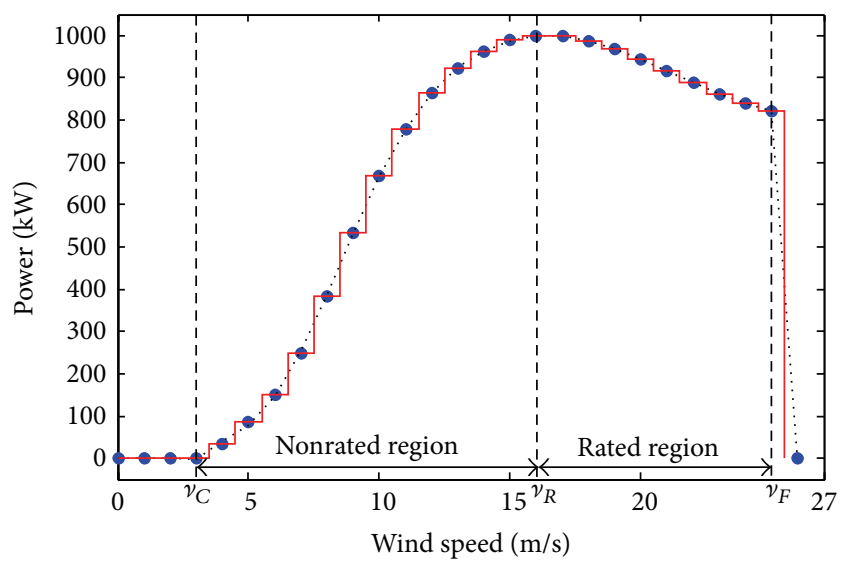

- Manufacturer data

.... Polynomial fitting

— ZOH fitting

Figure 3: Power curve of NEG Micon 1000/60 fixed speed wind turbine.

is $1 \mathrm{~m} \cdot \mathrm{s}^{-1}$. For example, consider a NEG Micon 1000/60 fixed speed turbine power curve, given in Table 1 . The turbine is stall regulated; therefore, the output power in the rated region reduces with the increase of wind speed, as shown in Figure 3.

The power curve data, provided by the manufacturer, may be extrapolated using either Zero Order Hold $(\mathrm{ZOH})$ method [4] or polynomial fitting [3], as shown in Figure 3. In the former case, each data point $P\left(v_{i}\right)$ is replaced by a $1 \mathrm{~m} \cdot \mathrm{s}^{-1}$ wide discrete bin, having the same magnitude, thus creating the following staircase approximation of the power curve:

$$
P_{\mathrm{ZOH}}(v)=P\left(v_{i}\right), \quad v_{i}-0.5 \leq v<v_{i}+0.5,
$$

for $i=1, \ldots, N$.

In the latter case, the data is divided into nonrated and rated subsets and each subset is fitted to a distinct polynomial, creating the following polynomial approximation of the power curve:

$$
P_{\mathrm{POLY}}(v)=P_{R} \begin{cases}0, & v<v_{C} \\ \sum_{i=0}^{n} a_{1 i} v^{i}, & v_{\mathrm{C}} \leq v \leq v_{R} \\ \sum_{i=0}^{n} a_{2 i} v^{i}, & v_{R} \leq v \leq v_{F} \\ 0, & v>v_{F} .\end{cases}
$$

\section{Capacity Factor Calculation}

In case the raw wind data of the site at hub height is available, a discrete PDF in the histogram form, described by (2), may be constructed. Hence, combining (2) and (8) as

$$
P_{\mathrm{ZOH}}(v) f_{\mathrm{HST}}(v) \cong P\left(v_{i}\right) f\left(v_{i}\right), \quad v_{i}-0.5 \leq v<v_{i}+0.5,
$$

and substituting into (1), the quasiexact solution for capacity factor is given by

$$
\mathrm{CF}_{\mathrm{QE}}=\frac{1}{P_{R}} \sum_{i=1}^{N} P\left(v_{i}\right) f\left(v_{i}\right) .
$$

The approximate solution for capacity factor is obtained by substituting (3) and (9) into (1) as [3]

$$
\begin{aligned}
\mathrm{CF}_{\mathrm{AN}}= & -\sum_{i=0}^{n} a_{2 i} v_{F}^{i} e^{-\left(v_{F} / c\right)^{k}} \\
& -\sum_{i=1}^{n} c^{i} \frac{i}{k} \Gamma\left(\frac{i}{k}\right) \\
& \times\left[a_{1 i} \gamma\left(\left(\frac{v_{C}}{c}\right)^{k}, \frac{i}{k}\right)-\left(a_{1 i}-a_{2 i}\right)\right. \\
& \left.\times \gamma\left(\left(\frac{v_{R}}{c}\right)^{k}, \frac{i}{k}\right)-a_{2 i} \gamma\left(\left(\frac{v_{F}}{c}\right)^{k}, \frac{i}{k}\right)\right],
\end{aligned}
$$

where

$$
\gamma(y, x)=\frac{1}{\Gamma(x)} \int_{0}^{y} t^{x-1} e^{-t} d t
$$

is the incomplete Gamma function. 
TABLE 4: 2008 monthly and yearly $10 \mathrm{~m}$ height statistical parameters.

\begin{tabular}{|c|c|c|c|c|c|c|c|c|c|c|c|c|c|}
\hline & Jan. & Feb. & Mar. & Apr. & May & Jun. & Jul. & Aug. & Sep. & Oct. & Nov. & Dec. & Year \\
\hline$c$ & 6.66 & 6.04 & 5.52 & 5.16 & 4.40 & 4.63 & 4.56 & 4.59 & 4.46 & 3.89 & 4.62 & 4.35 & 5.08 \\
\hline$k$ & 2.32 & 2.33 & 2.19 & 2.19 & 2.08 & 2.26 & 2.81 & 2.78 & 2.02 & 2.33 & 2.18 & 2.03 & 2.08 \\
\hline$\mu$ & 5.90 & 5.37 & 4.88 & 4.58 & 3.90 & 4.11 & 4.06 & 4.08 & 3.96 & 3.45 & 4.12 & 5.62 & 4.50 \\
\hline$\sigma$ & 2.68 & 2.40 & 2.36 & 2.19 & 1.95 & 1.92 & 1.58 & 1.60 & 2.04 & 1.56 & 1.94 & 2.91 & 2.26 \\
\hline
\end{tabular}

TABLE 5: Comparison of 2008 monthly capacity factors.

\begin{tabular}{lcccccccccccc}
\hline & Jan. & Feb. & Mar. & Apr. & May & Jun. & Jul. & Aug. & Sep. & Oct. & Nov. & Dec. \\
\hline $\mathrm{CF}_{\mathrm{QE}}$ & 0.5922 & 0.5341 & 0.4691 & 0.4249 & 0.3225 & 0.3546 & 0.343 & 0.3464 & 0.3324 & 0.2437 & 0.3525 & 0.5411 \\
$\mathrm{CF}_{\mathrm{AN}}$ & 0.5908 & 0.5302 & 0.4643 & 0.4194 & 0.3165 & 0.3485 & 0.3372 & 0.3405 & 0.3265 & 0.2376 & 0.3465 & 0.5398 \\
$\mathrm{CF}_{\mathrm{AP}}$ & 0.6425 & 0.5598 & 0.4834 & 0.4366 & 0.3305 & 0.3633 & 0.3555 & 0.3586 & 0.3399 & 0.2603 & 0.3648 & 0.5988 \\
\hline
\end{tabular}

As demonstrated in [4], CF against $\mu_{v}$ of any horizontal wind turbine under Rayleigh winds possesses S-shaped behavior with a linear region in the range of average wind speeds. In this linear region, the CF was shown to obey the following relation:

$$
\mathrm{CF}=0.087 \mu_{v}-\frac{P_{R}}{D^{2}}
$$

with $\mu_{v}$ given in $\mathrm{m} / \mathrm{s}, P_{R}, \mathrm{~kW}$, and the rotor blade diameter $D, \mathrm{~m}$. In the range of capacity factors of 0.15 to $0.45,(14)$ was shown to be accurate to within $10 \%$ for eight turbines of various rated powers and rotor diameters. Nevertheless, this simple CF relationship, while being very handy since it only requires the rated power and rotor diameter for the wind turbine and average site wind speed, is only valid for a limited range of wind speeds. Outside this range, the CF versus average wind speed curve can be no longer approximated by the derived linear relationship. In order to approximate the CF curve for the whole range of average wind speeds, the following nonlinear relationship was proposed in [5]:

$$
\begin{aligned}
\mathrm{CF}_{\mathrm{AP}}=(1-0.087) \cdot & {\left[\tanh \left(\frac{0.087 \mu_{v}^{2}}{2 \pi\left(1+P_{R} / D^{2}\right)+P_{R} / 2 D^{2}}\right)\right.} \\
& \left.-\frac{0.087}{2 \pi\left(1-P_{R} / D^{2}\right) \mu_{v}}\right] .
\end{aligned}
$$

Although nonlinear, (15) requires rated power and rotor diameter for the wind turbine and average site wind speed only, similar to (14). Calculating the CF using (15) is referred to as "approximate" approach in the paper.

\section{Case Study}

Consider a NEG Micon 1000/60 fixed speed stall-controlled wind turbine planned to operate under the wind conditions of Ariel, Israel. The turbine parameters are summarized in Table 2 and its power curve is given in Table 1. Coefficients of fitting the turbine power curve to 6th-order polynomials are shown in Table 3.
The statistical parameters of $10 \mathrm{~m}$ height winds are summarized in Table 4 . The 2008 monthly wind raw data in Ariel (10 min resolution) at $70 \mathrm{~m}$ height is shown in Figure 4 along with the appropriate histograms and fitted Weibull PDFs. The $70 \mathrm{~m}$ height wind speed data was extrapolated from the $10 \mathrm{~m}$ height data, provided by the Israeli Meteorological Service, using the following relation [4]:

$$
\frac{v_{70}}{v_{10}}=\left(\frac{70}{10}\right)^{0.3} \text {. }
$$

The resulting "quasiexact," "analytic", and "approximate" capacity factors, calculated using (11) and (13), accordingly, are summarized in Table 5 and plotted in Figure 5.

According to Table 5 and Figure 5, the "quasiexact" and "analytical" results are very alike with the largest and smallest errors in October and January, respectively. The "approximate" approach results slightly overestimate the CF since the monthly winds are not exactly Rayleigh with $k>2$. Two interesting points arise from the case study. First, the quasiexact capacity factor is higher than the analytic throughout the year. Second, the higher the capacity factor is, the lower the difference between the results is; that is, the October capacity factor is the year lowest, while the January capacity factor is the year highest.

\section{Conclusion}

Three approaches to fixed speed wind turbines capacity factor estimation were presented and compared in the paper using a case study. The "quasiexact" approach, which utilizes discrete wind raw and manufacturer-provided turbine power curve data, is only able to numerically calculate the capacity factor. The "analytical" approach, while being an approximation (since it utilizes continuous approximation of wind and power curve data), results in an analytical solution and hence provides a deeper understanding of the factors, affecting the capacity factor and several other merits of wind turbine performance, based on the analytically derived equations. The "approximate" approach, valid in case of Rayleigh winds only, employs a nonlinear approximation of the capacity factor versus average wind speed curve, only requiring rated 

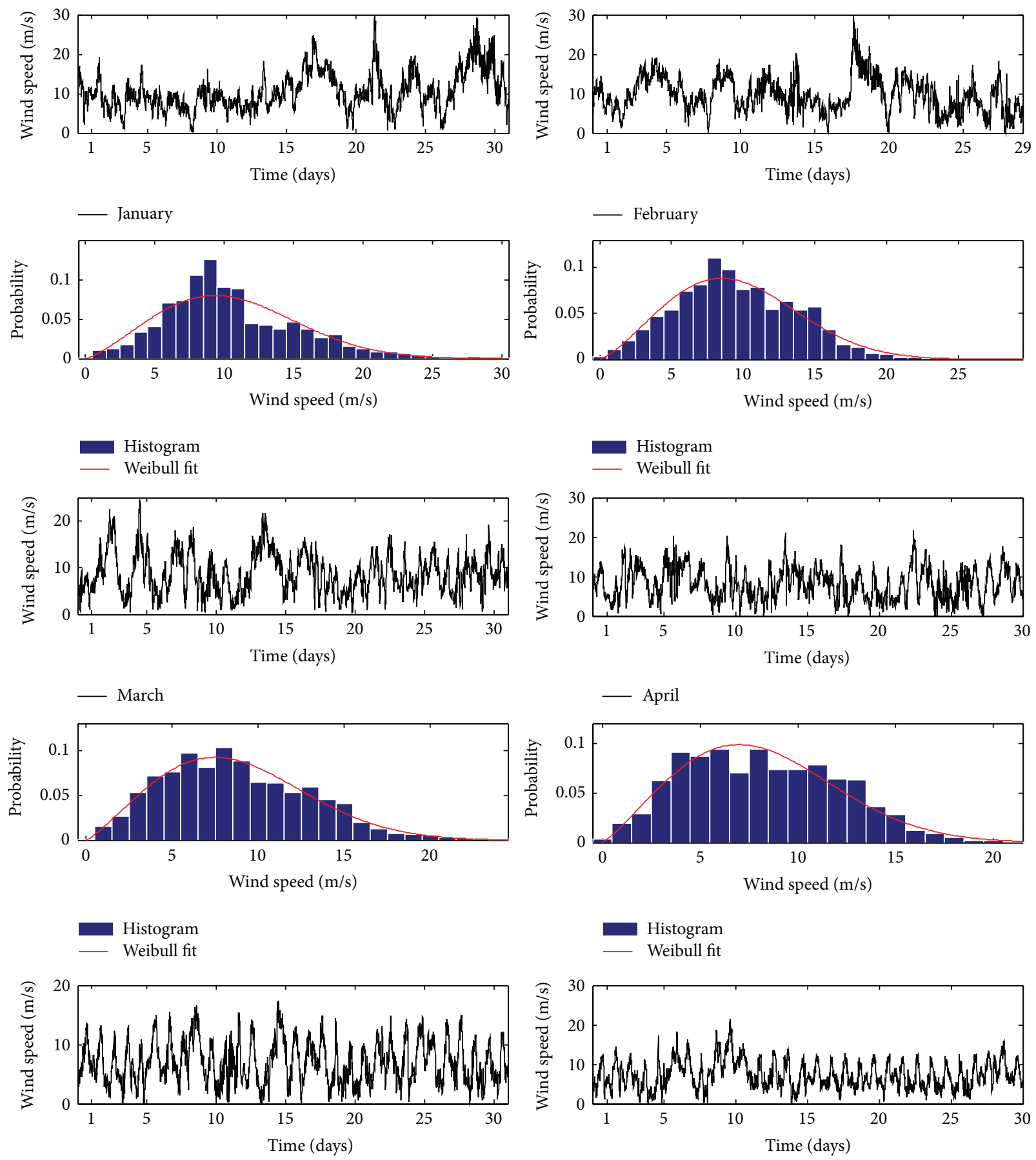

— May

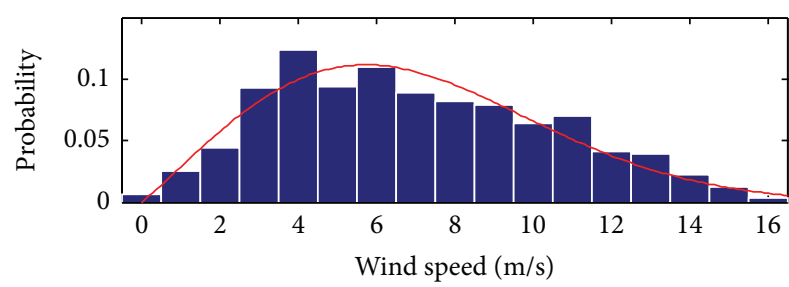

— June

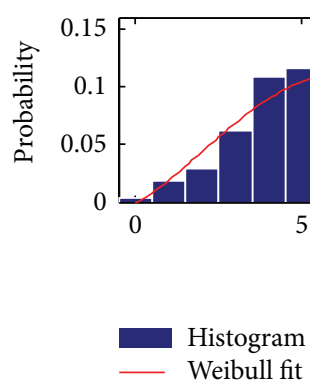

(a)

FIgURE 4: Continued. 

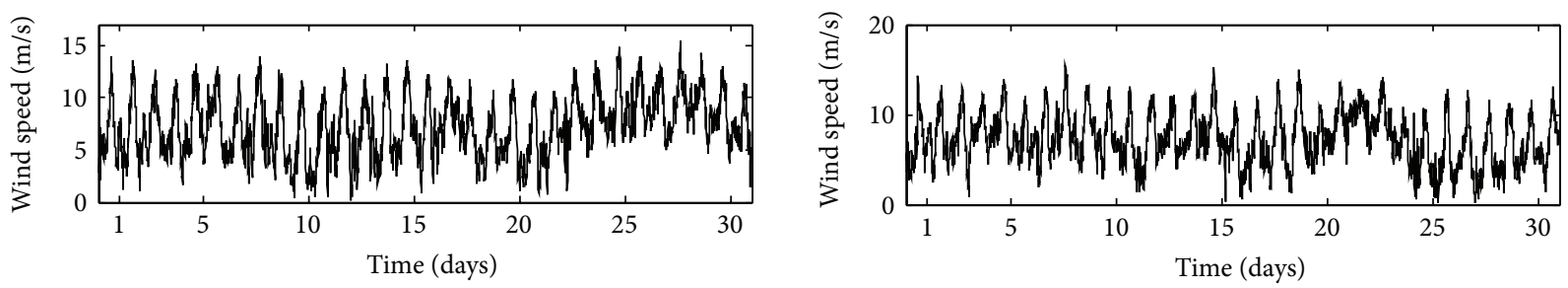

- July
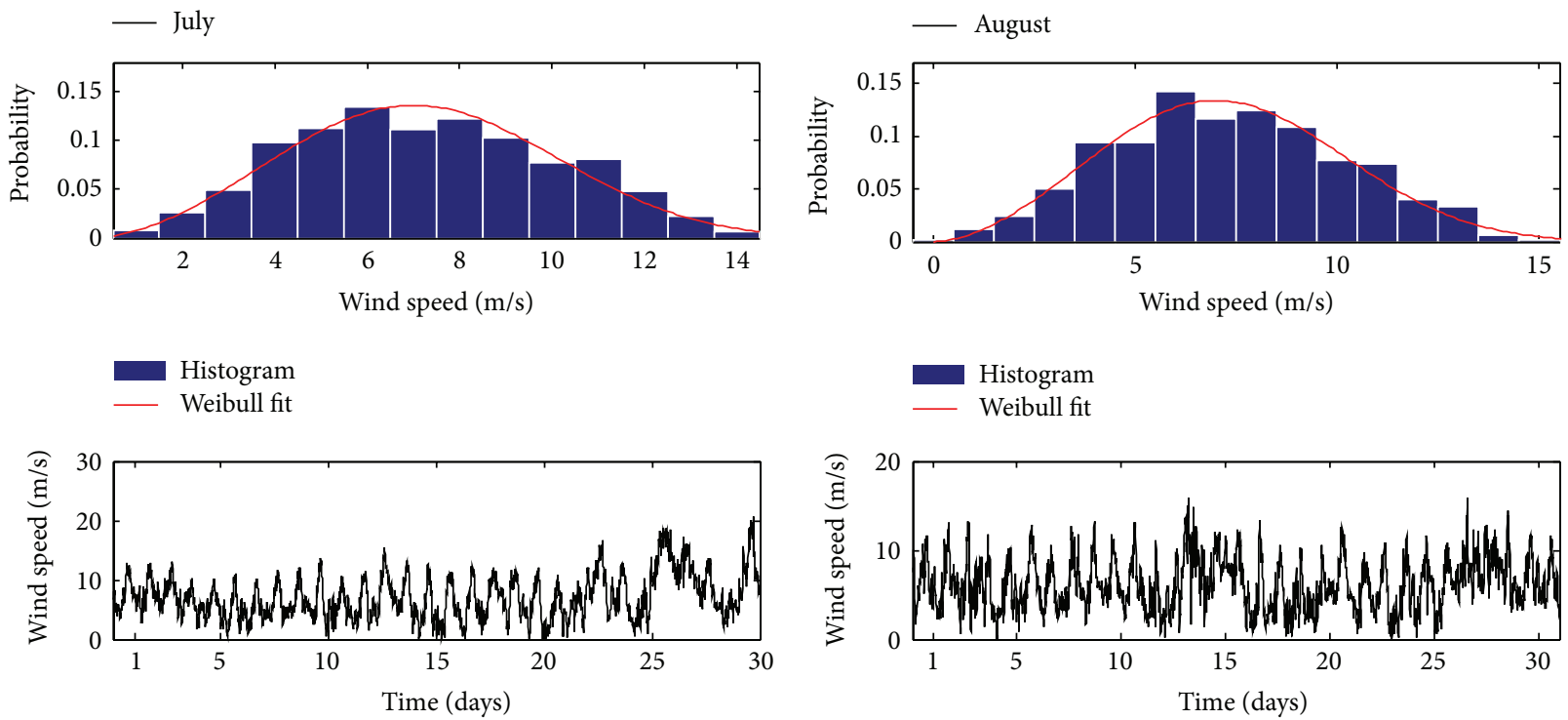

- September

- October

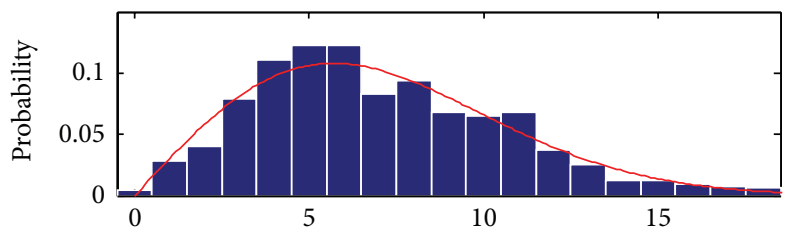

Wind speed $(\mathrm{m} / \mathrm{s})$
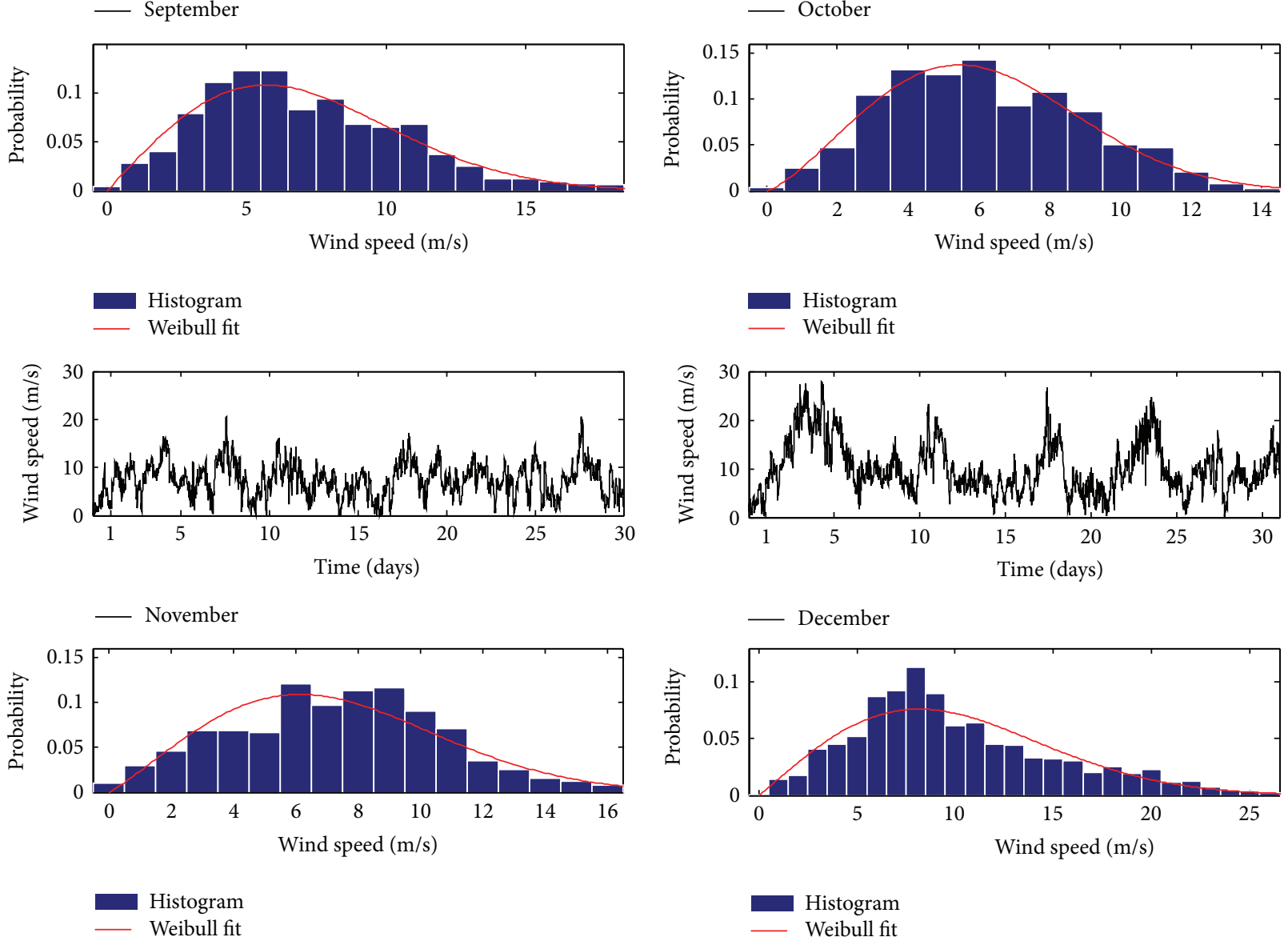

(b)

FIgURE 4: Monthly 2008 wind raw data in Ariel and appropriate PDFs. 


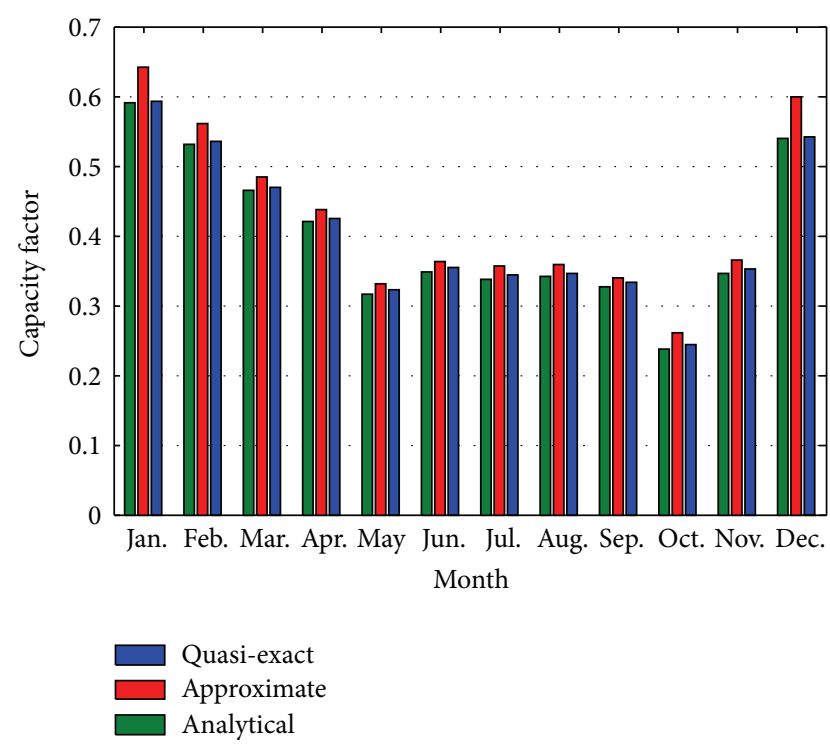

FIGURE 5: 2008 monthly capacity factors.

power and rotor diameter of the turbine. The paper has revealed the close similarity between the results obtained by employing the approaches, enforcing the validity of the analytically derived approximations.

\section{Conflict of Interests}

The authors declare that there is no conflict of interests regarding the publication of this paper.

\section{Acknowledgment}

The authors would like to thank the Israeli Meteorological Service for providing the Ariel wind raw data.

\section{References}

[1] K. A. Abed and A. A. El-Mallah, "Capacity factor of wind turbines," Energy, vol. 22, no. 5, pp. 487-491, 1997.

[2] M. H. Albadi and E. F. El-Saadany, "New method for estimating CF of pitch-regulated wind turbines," Electric Power Systems Research, vol. 80, no. 9, pp. 1182-1188, 2010.

[3] Y. Ditkovich, A. Kuperman, A. Yahalom, and M. Byalsky, "A generalized approach to estimating capacity factor of fixed speed wind turbines," IEEE Transactions on Sustainable Energy, vol. 3, no. 3, pp. 607-608, 2012.

[4] G. Masters, Renewable and Efficient Electric Power Systems, John Wiley \& Sons, New York, NY, USA, 2004.

[5] Y. Ditkovich, Matching wind turbines with wind regime in Samaria. [Master thesis], Ariel University, Israel, 2013.

[6] S. H. Jangamshetti and V. Guruprasada Rau, "Normalized power curves as a tool for identification of optimum wind turbine generator parameters," IEEE Transactions on Energy Conversion, vol. 16, no. 3, pp. 283-288, 2001.

[7] Y. Ditkovich, A. Kuperman, A. Yahalom, and M. Byalsky, "Sitedependent wind turbine performance index," International
Journal on Renewable Energy Research, vol. 3, no. 3, pp. 5925594, 2013.

[8] S.-Y. Hu and J.-H. Cheng, "Performance evaluation of pairing between sites and wind turbines," Renewable Energy, vol. 32, no. 11, pp. 1934-1947, 2007.

[9] T. P. Chang, "Performance comparison of six numerical methods in estimating Weibull parameters for wind energy application," Applied Energy, vol. 88, no. 1, pp. 272-282, 2011. 


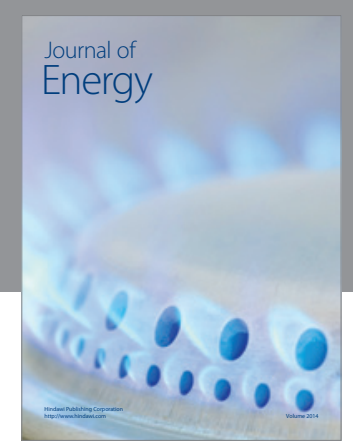

Journal of

Industrial Engineering
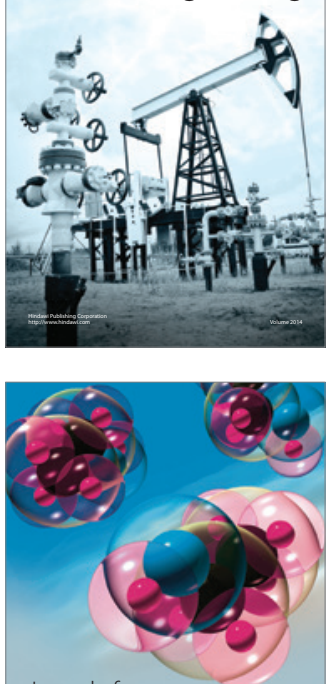

Fuels
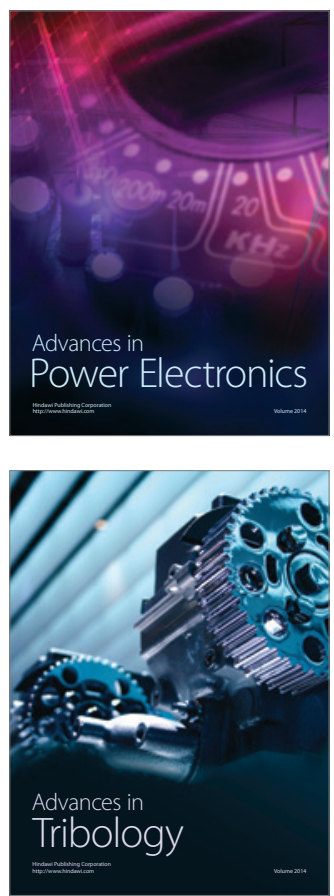

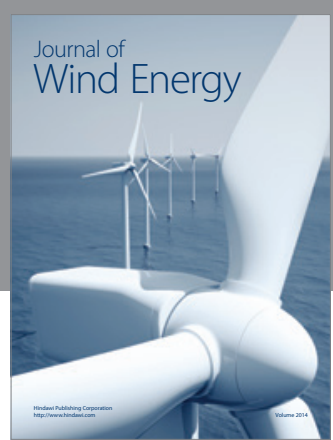

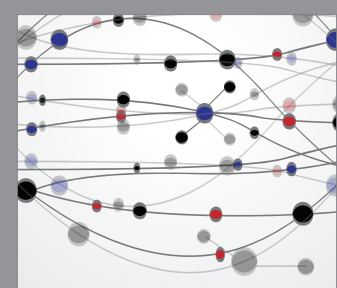

The Scientific World Journal

Submit your manuscripts at http://www.hindawi.com

Journal of

Structures
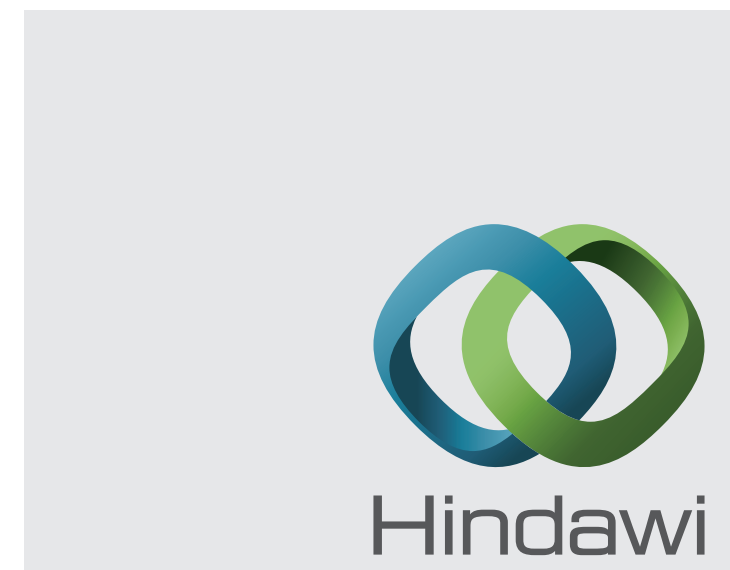

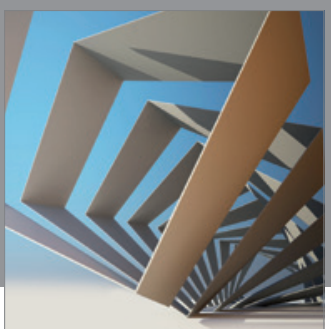

Rotating

Machinery
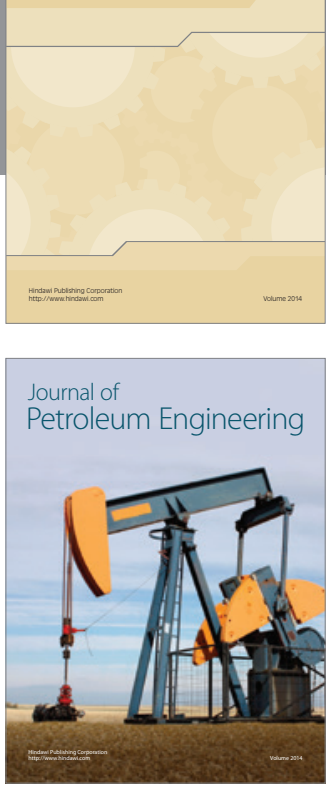

Journal of

Solar Energy
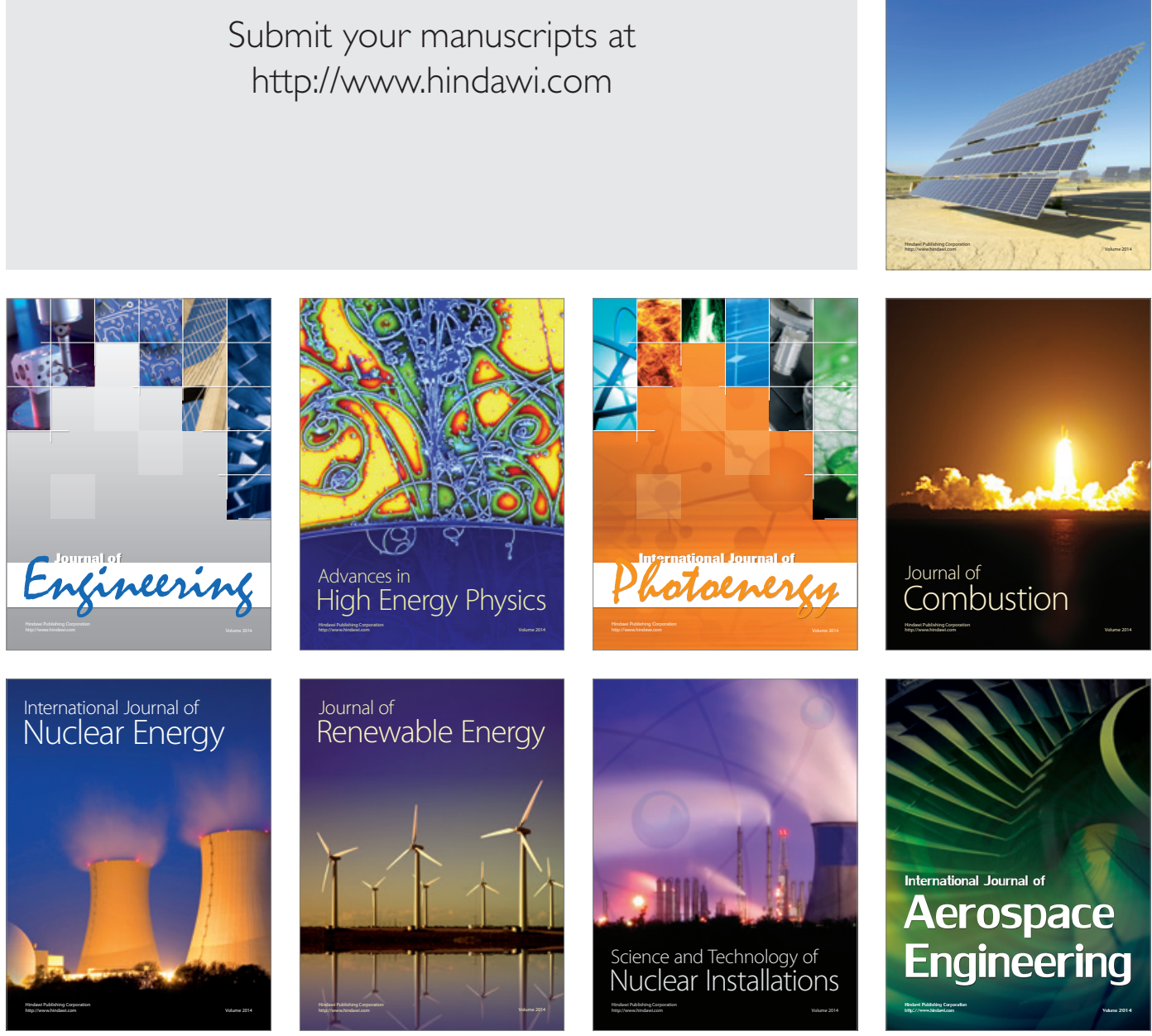